\title{
Las máximas de experiencia en la valoración racional de la prueba: Uso adecuado e inadecuado desde la perspectiva de género $\left.{ }^{*}\right)$
}

\author{
Maxims of experience in the rational assessment of evidence: Proper and \\ improper use from a gender perspective
}

\author{
Raquel Limay Chavez(*) \\ Universidad Nacional Mayor de San Marcos (Lima, Perú)
}

\begin{abstract}
Resumen: El presente trabajo pretende analizar doctrinaria, legal y jurisprudencialmente las denominadas máximas de experiencia en la valoración probatoria desde dos perspectivas: racional o epistemológica y de perspectiva de género. Ambos enfoques son relevantes; el primero, porque concibe a las máximas de experiencia como criterios de valoración de prueba y generalizaciones empíricas de forma condicional, susceptibles de ser catalogadas como verdaderas o falsas si no se corresponden con una constatación empírica. El segundo, porque permitirá poner en evidencia la indebida interpretación y aplicación de estos criterios de valoración como argumentos fundados sobre la base de sesgos, estereotipos o prejuicios de género-especialmente, en delitos sexuales-y que se ocultan bajo la denominación de máximas de experiencia del juez. El problema de interpretar los hechos a partir de prejuicios asignados a un género produce un inadecuado uso por parte de los juzgadores, que incide directamente en una valoración racional de la prueba, pues la convierte en una apreciación meramente subjetiva del juez no controlable de forma racional.
\end{abstract}

Palabras clave: Valoración racional - Perspectiva de género - Prueba - Máximas de experiencia - Estereotipos - Sesgos - Garantía

\begin{abstract}
The present paper intends a doctrinal, legal and jurisprudentially analysis of the so-called maxims of experience in the assessment of evidence from two perspectives: rational or epistemological and gender perspective. Both approaches are relevant because the first approach conceives the maxims of experience as assessment criterion and empirical generalizations with conditional form, susceptible to be classified as true or false if it does not correspond to an empirical verification. The second point of view, will allow showing the improper interpretation and application of these assessment criterion as arguments based on of biases and gender stereotypes, mainly, in sexual crimes, and that are hidden under the denomination of maxims of experience of the judge, this directly affects the rational assessment of evidence making this a simply subjective appreciation.
\end{abstract}

Keywords: Rational assessment - Gender perspective - Evidence - Maxims of experience - Stereotypes - Biases - Warrant

$\left.{ }^{*}\right) \quad$ Nota del Equipo Editorial: Este artículo fue recibido el 28 de junio de 2021 y su publicación fue aprobada el 1 de octubre de 2021.

${ }^{* *}$ Magíster en Razonamiento Probatorio por la Universidad de Girona (España) y Génova (Italia). Abogada por la Universidad Nacional Mayor de San Marcos, con estudios de Maestría en Ciencias Penales por la misma casa de estudios y en el Programa Internacional de Especialización en Argumentación Jurídica de la Universidad de Alicante. Fundadora del Instituto Peruano de Razonamiento Probatorio. Asesora jurisdiccional de la Corte Suprema de Justicia de la República del Perú en la Sala Penal para procesos de Altos Funcionarios del Estado. ORCID: https://orcid.org/0000-0001-9278-1067. Correo electrónico: r.limay@pucp.edu.pe. 


\section{Introducción: La búsqueda de la verdad como fín institucional en el proceso}

Uno de los debates que se ha generado en el campo de la filosofía se centra en la posibilidad de acceder a la verdad. Esta discusión no es exclusiva de dicha rama del conocimiento; a nivel jurídico, específicamente, en el marco de un proceso judicial, el debate respecto de la verdad se orienta a la posibilidad de que se pueda acceder a ella y, si fuera así, si se puede hacer de modo absoluto.

Dado que una investigación de las distintas teorías sobre la verdad extralimitaría el objetivo del presente trabajo, daré por supuesta aquella postura que afirma que un enunciado será verdadero en tanto refleje la realidad y se corresponda con ella (González, 2005, p. 97), argumento expuesto por la teoría de la verdad como correspondencia ${ }^{(1)}$. En esa línea de interpretación, desde un enfoque epistemológico, la actividad probatoria desplegada en el proceso deberá estar orientada a la búsqueda de la verdad - afirmación que no niega la posibilidad que también puedan concurrir otras finalidades - esta será siempre la finalidad institucional. Como bien lo ha señalado Taruffo (2002, p. 86), la verdad de la afirmación de los hechos es condición para una correcta aplicación de la norma, de ahí que la concepción de la búsqueda de la verdad, sea la que más ayude a la consecución de estos fines.

Ello es así, si entendemos que una de las principales funciones del derecho es la regulación de las conductas ${ }^{(2)}$. Para que esta función se cumpla, deben aplicarse las consecuencias jurídicas estipuladas en las normas a las descripciones fácticas prescritas en ella y siempre que, en efecto, las conductas se hayan producido. Solo bajo esta seguridad -que las normas se apliquen a los hechos que en realidad ocurrieron-, los destinatarios de las normas orientarán su actuar de conformidad con el derecho y este podrá cumplir su función de mecanismo de resolución de conflictos, de lo contrario, como lo refiere Ferrer: "si fuera el juez quien constituyera el antecedente fáctico de la aplicación de aquellas consecuencias, no podría motivarse la conducta de los ciudadanos puesto que esta resultaría irrelevante al efecto de esa aplicación" (2016, p. 50).

Pese a la exposición de estas razones, en América Latina, han sido mayoritarias las posturas que niegan que la finalidad del proceso y de sus instituciones -como la prueba- sea alcanzar el conocimiento de la verdad (Maier, 2004, p. 844)(3). Según estos sectores doctrinarios, la finalidad de la prueba estaría orientada a lograr la íntima convicción o persuasión del juzgador descartando de plano que la verdad sea un fin alcanzable. Sin embargo, asumir ello, implicaría aceptar que dicho estado mental podría verse satisfecho independientemente de la forma en que se llegue a este, incluso si no es acorde con los hechos realmente producidos, "conduciendo necesariamente a una concepción irracional de la prueba" (Ferrer, 2005, p. 67) ${ }^{(4)}$.

Una postura racional la expone Ferrer (2005, pp. 72-74) quien sostiene que la prueba como actividad ${ }^{(5)}$ cumple la función de

(1) Como lo ejemplifica Tarski (1931), la proposición "la nieve es blanca" es verdadera sí y solo sí, la nieve es blanca. Debe producirse una correspondencia entre lo que sostiene la proposición o enunciado y lo que ocurre en el mundo real.

(2) Ferrer (2016) refiere a que no desconoce la presencia entre el material jurídico de disposiciones que "no expresan prescripciones y que, por tanto, no dirigen directamente la conducta de nadie. Sin embargo, creo que puede decirse que la presencia de prescripciones entre ese material jurídico es consustancial a la idea de derecho" (pp. 49-50).

(3) El autor califica al procedimiento judicial como un método regulado jurídicamente, de investigación histórica, precisamente porque uno de sus fines consiste en el intento de averiguar la verdad acerca de la hipótesis histórica, positiva o negativa, que constituye el objeto del procedimiento. Sin embargo, este autor hace depender de la consideración subjetiva del juzgador la averiguación de la verdad, clasificándola por ejemplo de certeza positiva cuando el juez queda convencido.

(4) Sin embargo, suponiendo que esta fuera la finalidad de la prueba, se podría decir que "la íntima convicción" igualmente versaría respecto del objeto de prueba, que está constituido por los enunciados sobre los hechos controvertidos. Esta interpretación conllevaría a reafirmar que cualquiera sea el estado mental del juzgador, este deberá referirse a los enunciados fácticos, lo que en suma significa que, necesariamente, la finalidad de la prueba se vincula con la verdad de las proposiciones expuestas por las partes. Cabe acotar que en el proceso se prueban las afirmaciones sobre los hechos y no los hechos mismos. Como lo ejemplifica Serrá Domínguez, no puede probarse una mesa ni un contrato ni una obligación. Lo único que puede probarse es el enunciado que afirma la existencia la existencia de un contrato y no el contrato mismo (Ferrer, 2005, p. 70).

(5) Responde a la siguiente clasificación: prueba en el sentido de (i) medio de prueba, (ii) prueba como actividad y (iii) prueba como resultado. Accatino (2018), precisa, sobre estas distinciones, que (i) se refiere a los datos, o informaciones susceptibles de ser percibidas a través de los sentidos, que constituyen elementos de juicio a favor o en contra de la verdad de alguna afirmación relativa a un hecho jurídicamente relevante, (ii) la actividad consistente en introducir a un proceso judicial medios de prueba específicos a fin de que se funde en ellos la decisión judicial sobre los hechos del caso. Se trata de una actividad reglada, desarrollada fundamentalmente por las partes, en la forma y con los controles previstos por la ley y (iii) constituye el resultado de la valoración por el juez de los medios de prueba aportados al proceso (pp. 4-6). 
comprobar si los hechos expuestos se han producido o, lo que es lo mismo, a través de la actividad probatoria se determinará el valor de verdad de los enunciados que describen su ocurrencia. Así, cuando los medios de prueba son incorporados al proceso aportan elementos de juicio a favor de la verdad de un enunciado.

Podría entonces afirmarse la existencia de una relación entre los enunciados probatorios (del tipo "Está probado que p") respecto de los elementos de juicio (los medios de prueba) presentes en el caso judicial. Por lo que, "para que pueda decirse que una proposición está probada es necesario y suficiente que se disponga de elementos de juicio en su favor, que hagan aceptable esa proposición como descripción de los hechos del caso" (Ferrer, 2005, p. 69)(6). Se produce una relación de carácter teleológico entre prueba y verdad.

En ese sentido, la perspectiva epistemológica de la búsqueda de la verdad como fin institucional del proceso y de la actividad probatoria orientará mi propuesta sobre el tratamiento de las llamadas máximas de experiencia en una de las fases primordiales del proceso, la valoración probatoria( ${ }^{(7)}$.Asimismo, se empleará un perspectiva de género, de modo específico, para la identificación de problemáticas que pueden presentarse en la valoración.

\section{La valoración probatoria}

En el proceso judicial, se despliegan diversas etapas o momentos diferenciados y sucesivos en los cuales se desarrolla la actividad probatoria. Ferrer (2007) explica que consisten en:

(i) La conformación del conjunto de elementos de juicio sobre cuya base se adoptará la decisión (que a su vez se divide en fase de admisión y práctica de la prueba), (ii) la valoración de esos elementos; y, c) propiamente, la adopción de la decisión (p. 41).

El tema que abordaré se ubica de modo concreto en la etapa de valoración probatoria, una de las fases primordiales del proceso, consistente en la dotación u otorgamiento de valor de los elementos de prueba de modo individual y conjunto. Se indica que es un momento trascendental dado que de ella depende que el juez establezca la decisión final en el proceso penal (Taruffo, 2009, p. 421).
Al respecto, la doctrina peruana considera que la valoración consiste en extraer una conclusión a partir de la información obtenida en el contexto procesal (San Martín, 2015, p. 590) y se ejecuta a través de una operación intelectual realizada por el juzgador para determinar si se consideran probados los datos fácticos, por lo que, involucra un análisis razonado de los elementos introducidos en el proceso (Claría, 1998, p. 307).

En esa línea de interpretación, se puede sostener que la valoración de la prueba se constituye en aquella actividad probatoria, a cargo exclusivo del órgano jurisdiccional, consistente en un trabajo intelectivo respecto de la verificación de las afirmaciones fácticas sostenidas por las partes. Los sistemas jurídicos como el peruano, de raigambre romano-germánica, establece un régimen de libre valoración de la prueba, -para diferenciarlos de los antiguos sistemas de prueba legal o tasada o de la íntima convicción ${ }^{(8)}$-, que exige que la apreciación del juez se realice en relación de los elementos de juicio que aportan las partes del proceso para el esclarecimiento de la hipótesis fáctica a ser demostrada.

A mayor especificación, como lo refiere Ferrer (2016), la actividad de valoración es libre en el sentido que no está sujeta a normas jurídicas que predeterminan su resultado. Adicional a ello, la operación consistente en juzgar el apoyo empírico que aporta el conjunto de elementos de juicio a la hipótesis se encuentra sujeta a los criterios generales de la lógica y la racionalidad (p. 155). De lo anterior, como acota Fernandéz, "la existencia de criterios racionales de apreciación de la prueba ha permitido, como puede deducirse fácilmente, la posibilidad de ejercer un verdadero control sobre esta actividad judicial

(6) Explica Ferrer que esta afirmación pondría en tela de juicio aquella que sostiene la relación conceptual entre prueba y verdad. Esto es, "aquella que consiste en postular a la verdad de un enunciado como condición necesaria para que pueda decirse que ha quedado probado" (2005, p. 68).

(7) La epistemología no está interesada simplemente en la reducción de errores y el derecho tampoco. La justificación de una decisión sobre los hechos tiene una doble cara (o hay dos tipos de justificaciones, si se prefiere): una material y una procedimental. Desde el primer punto de vista, podemos decir que una decisión está justificada si la proposición que se declara probada es verdadera. En el sentido procedimental, en cambio, la decisión está justificada si la hipótesis que se declara probada tiene suficiente apoyo en los elementos de juicio disponible (Ferrer, 2007, p. 101).

(8) Este último aún contenido en la normativa procesal penal peruana del Código de Procedimientos Penales de 1940, vigente en algunos distritos judiciales del Perú. 
cuando se entiende que no se ha realizado conforme a los mismos" (2005, p. 238).

En ese sentido, si bien la valoración de las pruebas no se rige bajo el cumplimiento de normas tasadas que predeterminen cómo el juez deberá valorar determinadas pruebas ni qué valor otorgarles, no significa de ningún modo "libre arbitrio, ni la posibilidad de entrada a la "ciencia privada", por el contrario, conlleva a la obligación de razonar el resultado probatorio en la declaración de los hechos probados" (Gimeno, 2012, p. 381). Por ello, se sostiene que es una valoración de acuerdo con las reglas de la sana crítica o una valoración racional. Antes de analizar qué entiende nuestra legislación por este sistema de valoración, veamos seguidamente la perspectiva de género que también será aplicable a la valoración probatoria.

\section{Perspectiva de género en la valoración probatoria}

Como claramente lo acota la profesora de la Universidad de Alicante, Fernández (2005):

La legitimidad de los órganos jurisdiccionales no descansa únicamente en la posesión de su cargo, sino que deriva también de la emisión de resoluciones judiciales acertadas, basadas en criterios racionales, de tal modo que es necesario que se exija la expresión del razonamiento que ha llevado a un juez a dictar una resolución (p. 242)

Al respecto, Ramírez argumenta que "en el ámbito jurídico la perspectiva de género puede servir para desvelar aquellas instituciones, reglas y prácticas del derecho que crean, legitiman y perpetúan la discriminación, con el propósito de derogarlas, transformarlas y/o sustituirlas por otras" (2020, p. 203). El citado autor identifica que, en todo razonamiento humano, al cual no es ajeno el razonamiento judicial existen diversos sesgos que son aplicados. Así ubica dentro de estos a los sesgo de grupo. De acuerdo con este, "el sujeto valora de forma homogénea las acciones y opiniones de las personas que pertenecen al mismo grupo, por la sola razón de pertenencia a ese grupo. Esos prejuicios pueden ser tanto positivos, como negativos" (p. 228).

Como lo refiere el citado profesor español, el sesgo de grupo se correlaciona con el concepto de estereotipo, entendido como preconcepción sobre las características de los miembros de un colectivo o sobre los roles que deben cumplir. Ello se convierte en un riesgo si es que estos estereotipos son aplicados por un juez con cultura machista, pues sobre ellos puede decidir el sentido de su decisión, en tanto los estereotipos de género, pueden justificar que el juez decida fundándose en aspectos como las características de la personalidad, comportamientos y roles, características físicas y apariencia u ocupaciones y presunciones sobre la vida y orientación sexual de determinada persona, en este caso de la víctima, entre ellos se encuentran los estereotipos de roles sexuales (Ramírez, 2020, p. 229).

En ese razonamiento, el papel que la perspectiva de género puede desempeñar en el ámbito de la disciplina probatoria es importante, como en la etapa de valoración de las pruebas, en tanto que permite al juzgador identificar los estereotipos subyacentes en sus evaluaciones y a las partes controlar la motivación o justificación que empleó el órgano jurisdiccional en caso de haberse identificado. Así, la perspectiva de género permite desactivar y poner en evidencia las falsas máximas de la experiencia (Ramírez, 2020, p. 230) que podrían cubrir a un estereotipo o prejuicio de género.

Cabe acotar que, como lo sostiene Fuentes (2020, p. 274), el rol de la perspectiva de género no solo queda circunscrita al exclusivo momento de la valoración probatoria sino también, desde una perspectiva dinámica, se puede analizar su influencia en los distintos momentos de la actividad probatoria y sobre las diferentes fuentes de prueba. La citada autora afirma que, en el momento en el cual el juez interprete la ley, la perspectiva de género cumple un rol fundamental para desterrar prácticas o interpretaciones que perpetúen y legitimen los estereotipos de género.

Así, frente a un caso judicial en el que necesariamente deben interpretarse los hechos para la posterior aplicación de la norma (análisis fáctico - jurídico de toda decisión judicial) $)^{(9)}$, se debe admitir en principio, como lo refiere Raymundo Gama, que:

Un mismo hecho puede ser interpretado de distintas maneras y que entre los criterios que utilizamos para llevar a cabo tales

(9) Respecto a la relación entre hechos y derecho, Fernández (2005, p. 243) acota que "se trata de la sumisión judicial también -y fundamentalmente- a los hechos objeto del proceso" o, como señala Muñoz Conde, "a la realidad implacable de los hechos a los que dicha ley tiene que ser aplicada". 
interpretaciones pueden estar presentes construcciones de género, sesgos, prejuicios, creencias, etc. Nuestras interpretaciones de los hechos, por tanto, son susceptibles de examinarse desde la perspectiva de género (2020, p. 292).

En ese sentido, es posible afirmar que "juzgar con perspectiva de género equivale a implementar en el enjuiciamiento técnicas que faciliten la consecución del objetivo de la igualdad efectiva de mujeres y hombres en el uso y disfrute de los derechos y libertades" (García \& Subijana citado en Fuentes, 2020, p. 276). En función de este enfoque se evaluará la etapa de valoración probatoria, identificando posibles problemáticas de argumentación en el razonamiento jurídico que asuma dicha índole.

\section{Valoración probatoria del Código Procesal Penal peruano}

Definida la valoración probatoria, además de identificar que el sistema peruano responde a un sistema de libre valoración y la incidencia de la perspectiva de género en este momento procesal, conviene ahora apreciar cómo se encuentra regulada en la legislación peruana. La norma procesal que rige el sistema procesal peruano es el Código Procesal Penal de 2004 (en adelante, CPP) que alude a la valoración probatoria en los siguientes textos normativos:

El artículo 158.1 prevé sobre la valoración, que:

En la valoración de la prueba el juez deberá observar las reglas de la lógica, la ciencia y las máximas de la experiencia, y expondrá los resultados obtenidos y los criterios adoptados.

El artículo 393 que regula las normas para la deliberación y votación, específica que:

1. El juez penal no podrá utilizar para la deliberación pruebas diferentes a aquellas legítimamente incorporadas en el juicio.

2. El juez penal para la apreciación de las pruebas procederá primero a examinarlas individualmente y luego conjuntamente con las demás. La valoración probatoria respetará las reglas de la sana crítica, especialmente conforme a los principios de la lógica, las máximas de la experiencia y los conocimientos científicos.

El artículo 156 indica en cuanto al objeto de prueba, que:

1. Son objeto de prueba los hechos que se refieran a la imputación, la punibilidad y la determinación de la pena o medida de seguridad, así como los referidos a la responsabilidad civil derivada del delito.

2. No son objeto de prueba las máximas de la experiencia, las Leyes naturales, la norma jurídica interna vigente, aquello que es objeto de cosa juzgada, lo imposible y lo notorio.

En cuanto a la regulación descrita, se pueden efectuar las siguientes acotaciones.
De acuerdo con el sistema de valoración, el artículo 158.1 del CPP prevé que la valoración judicial se guiará bajo tres tipos de reglas: de la lógica, las máximas de experiencia y la ciencia. En igual sentido, el artículo 393.2 indica que la valoración respetará los principios de la lógica, las máximas de experiencia y los conocimientos científicos. Finalmente, el artículo 156.2 regula que las reglas de valoración citadas previamente no son objeto de prueba.

En adelante, me centraré en las denominadas máximas de experiencia. De acuerdo con la redacción del legislador peruano, identifica a estas como una regla o principio de la valoración probatoria, esto es como un criterio que orienta o guía la actividad valorativa del tribunal jurisdiccional. En principio, para situarnos, con ejemplos gráficos se alude a las máximas de experiencia para dar por probado datos como "es una máxima de experiencia que todo cuerpo cae por efecto de la gravedad", o "es una máxima de la experiencia que aquel testigo que tiembla o mira a los costados está mintiendo" o aun otra "es una máxima de experiencia que aquel sujeto que huye corriendo de la escena del crimen es el primer sospechoso".

La importancia de sostener o justificar un argumento judicial utilizando este tipo de máximas de experiencia incide, sin duda, de modo determinante en la decisión judicial $y$, por consiguiente, en la situación jurídica del imputado. Por ello, en principio, analizaré cómo la doctrina y jurisprudencia ha interpretado a las máximas de experiencia. Luego de ello, determinaré si existe una posición unánime sobre su comprensión. Precisamente, se intentará formular una adecuada concepción sobre lo que debe entenderse por estas reglas y efectuar una correcta interpretación en consonancia con un sistema racional de valoración probatoria, cuyo fin es el de la determinación de la verdad de los hechos a ser probados.

\section{Las máximas de experiencia. Conceptos y clasificación}

\subsection{Contenido conceptual}

Las denominadas máximas de experiencia han sido estudiadas por diversos 
representantes de la doctrina procesal, quienes las han dotado de un contenido conceptual brindando alcances sobre lo que debemos entender por estas, mientras que otros inclusive han elaborado una clasificación de las mismas. Veamos cuáles son estas definiciones, sus coincidencias y diferencias.

La adopción y origen de la terminología empleada la encontramos por primera vez en Stein (1999) quien sostuvo que las máximas de experiencia serían:

Definiciones o juicios hipotéticos de contenido general, desligados de los hechos concretos que se han de juzgar en el proceso, procedentes de la experiencia, pero independientes de los casos particulares de cuya observación se han inducido y que, por encima de estos casos pretender tener validez para otros nuevos (p. 27).

Aunque Stein utilizó la terminología "máximas de experiencia" dejó abierta la posibilidad de un cambio en su denominación; sin embargo, el empleo de este término se masificó en la doctrina y jurisprudencia. Actualmente, podemos encontrar algunas definiciones que no parecen ser tan unívocas.

Así, por ejemplo, Abel Lluch refiere que constituyen reglas y no hechos y que, por consiguiente, no pueden ser objeto de prueba, por lo que, su tratamiento procesal a efectos de prueba debe ser similar al de la norma jurídica. Esto es, el juez debe aplicar las máximas de experiencia al margen de cualquier prueba por las partes. La máxima de experiencia es de carácter abstracto, no necesita ser alegada y no está sometida a contradicción, no precisan de prueba (2012, p. 108). Las máximas de experiencia en esta interpretación serían equivalentes a normas jurídicas aplicadas por el juez que no pueden ser discutidas.

Couture las define como normas de valor general, independientes del caso específico, que se extraen de la observación. Horvitz (2004), al respecto, indica que expresan normas de sentido común cuyo único fundamento es el hecho que forman parte de la cultura del hombre medio en un cierto lugar y en un cierto momento (p. 336). En este caso, se las identifica de modo genérico como normas del sentido común pertenecientes al hombre medio.

Por su parte, Cerda (2008) las identifica como:

Aquellos criterios de probabilidad objetiva, contingentes y mutables, que incluye las definiciones y juicios hipotéticos provenientes del conocimiento práctico de los hombres, pero también los conocimientos científicos y técnicos (...) no hay absolutamente ninguna máxima de la experiencia que no sea notoria (p. 55 y p. 59).

En este texto, las máximas son conocimientos prácticos o científicos provenientes de los sujetos.

De la Olivia considera que son reglas o normas de experiencia, reglas de naturaleza no jurídicas o reglas generales de carácter empírico (citado en Abel, 2012, p. 107), mientras que Bustamante refiere que estas poseen contenido general, independientes del caso concreto que han sido extraídas de la observación corriente del comportamiento humano, pueden ser conocidas por cualquier persona de cultura media (2015, p. 308). Se ha argumentado que las máximas de experiencia están conformadas por aquellas conclusiones extraídas de percepciones singulares pertenecientes a los más variados campos de conocimiento, como técnicos, científicos e incluso comunes. Esta regla es empleada por el juez como criterio para fundamentar sus razonamientos (Talavera, 2009, p. 111). Las tres definiciones identifican como normas de índole fáctica (no jurídica), pertenecientes al hombre de cultura media. Mientras la primera conceptualización las identifica como reglas generales, la segunda refiere que son producto de percepciones específicas.

Montero (2008), por su parte, considera que en el sistema de prueba libre las máximas de la experiencia se aplican por el juez, se extraen por este de su experiencia de la vida, y se deben aplicar a cada uno de los medios de prueba. No se trata de que el juez decida en conciencia sino de que aplique las (...) reglas de la sana crítica y estas reglas son simplemente máximas de experiencia (p. 438). El citado profesor cuando identifica a las máximas de experiencia se refiere a la experiencia del juez, es decir, no de un grupo humano ni de la sociedad, además, equipara las reglas de la sana crítica y las de máximas de experiencia, por lo que, estas últimas ya no se constituirían en criterios de la valoración, sino serían en sí misma la valoración de sana crítica.

Bonorino (2016, p. 308) sostiene que poseen un carácter empírico, su verdad o falsedad es contingente. Actúan como premisas (por lo general tácitas) en las argumentaciones probatorias, formando parte del conocimiento ordinario (...) se las denomina leyes y son enunciados condicionales generales, pero su estructura profunda no es la misma que la de las leyes de la lógica, porque son condicionales derrotables. En similar razonamiento, 
Fernández (2007)(10) sostiene que "la conclusión (en la valoración) ha de alcanzarse a partir de las premisas, gracias a la aplicación de una máxima de experiencia -común o especializada- bien fundada" (p. 3). Ambas disquisiciones las equiparan como premisas del razonamiento judicial.

Para concluir con esta lista de definiciones, Taruffo (2011, p. 219) refiere que son nociones derivadas de la experiencia común que representan la base de conocimientos generales para la valoración de la prueba, pero que expresan nociones de sentido común que tienen como único fundamento el hecho de formar parte de la cultura del hombre medio en cierto lugar y en cierto momento. En esta concepción nuevamente se asemejan a las máximas de experiencia como producto del conocimiento común y que se instituyen en instrumentos de valoración.

De las posturas doctrinarias recopiladas, se puede concluir, en principio, que no precisan de un concepto unívoco y en más de una ocasión, sus concepciones se oponen. Siendo las diferencias más resaltantes las siguientes:

- Por un lado, son consideradas normas jurídicas, mientras que por otro se indica que no son reglas jurídicas sino empíricas o fácticas.

- Se indica que son producto del conocimiento común, general del hombre medio, pero se ha sostenido, en otro extremo, que se constituyen en la experiencia del juez.

- Se señala que derivan de casos generales, pero también se indica que son producto de percepciones concretas.

- Se acota que son instrumentos o reglas para la valoración probatoria libre o en sana crítica. Sin embargo, sin establecer esta función instrumental, se ha precisado que las máximas de experiencia serían en sí mismas las reglas de la sana crítica.

- Finalmente, se sostiene que las máximas de experiencia no deben ser objeto de prueba.

En suma, existe una disparidad en su conceptualización que conviene ser esclarecida.

\subsection{Respecto a la clasificación}

En cuanto a la clasificación de las máximas de experiencia, también la doctrina ha pretendido formular diversas propuestas, González (2012, p. 20) ha sostenido que las máximas de experiencia pueden ser: (i) de carácter científico o especializado, como las que aportan los peritos; (ii) de carácter jurídico, como las derivadas del ejercicio profesional del juez; o (iii) de carácter privado (experiencias corrientes), esto es, derivadas de las experiencias del juez al margen del ejercicio de su profesión.

Por su parte, Cerda (2008, p. 64) clasifica a las máximas de experiencia en legales y fácticas. Las primeras serían las presunciones establecidas por el ordenamiento jurídico mientras que las segundas estarían constituidas por los conocimientos generales del hombre medio. Una postura en contra la expone Abel (2012, p. 107) cuando sostiene que no se debe confundir las máximas de experiencia con presunciones, porque las primeras son reglas, mientras que las presunciones constituyen un método de razonamiento dirigido a la prueba de un hecho determinado.

Schum \& Twinning (2015, p. 141 y p. 325 ) las clasifican empleando cuatro ejes:

- De generalidad o nivel de abstracción, marcados por generalizaciones abstractas y en los casos o contextos concretos.

- De confiabilidad o de grado de certeza, dentro de la cual pueden identificarse en primer término, a las leyes científicas, las opiniones científicas bien fundadas, las conclusiones ampliamente compartidas basadas en la experiencia común, ocupando un segundo lugar, las creencias comúnmente afirmadas pero no probadas e improbables, y finalmente, en último lugar, se encontrarían los prejuicios y sesgos arraigados con independencia de los datos disponibles y las creencias menos arraigadas pero operativas.

- De fuente o base, basadas en la experiencia personal reiterada y aquellas fundamentadas en el conocimiento obtenido de generalizaciones sintéticointuitivas.

- Del grado de coincidencia, referido a cuán ampliamente podría la generalización ser aceptada o compartida al interior de una particular comunidad en la que un problema deba ser resuelto ${ }^{(11)}$.

(10) En la sentencia 1710-2002-AA, resuelta por el Tribunal Constitucional, el 18 de octubre, se alude a las máximas de experiencia como "pautas útiles o reglas de experiencia, como parámetros de contraste para fundamentar una sentencia condenatoria".

(11) Incluyen además como ejemplos de generalizaciones ubicadas dentro de los ejes mencionados, aquellas adquiridas a través de la experiencia o del estudio, las que son universal o ampliamente compartidas dentro de la comunidad relevante, las basadas en un tipo de prejuicio, las fundadas en principios científicos o matemáticos, las derivadas de experiencias comunes (Anderson et al., 2015, p. 325). 
Al respecto, de la clasificación de las denominadas máximas de experiencia, conviene sostener que en esta tarea la doctrina tampoco ha sido unánime ni mayoritaria. Ahora bien, no resulta demasiado provechoso establecer una división o clasificación, pues en principio, de las conceptualizaciones enunciadas precedentemente, se puede extraer que las máximas de experiencia pueden variar de acuerdo a (i) un aspecto subjetivo, esto es, correspondiente a los conocimientos asumidos por diversos grupos humanos (incluidos los órganos jurisdiccionales), sociedades, comunidades científicas, entre otros, y (ii) objetivo, dependiendo del contexto social o el tiempo en que han tenido lugar.

Si ello es así, existirían tantas clasificaciones como sujetos, grupos y momentos en los cuales podrían identificarse. Por ello, me enfocaré más bien en su conceptualización y estructura lógica y solo abordaré su clasificación para identificarla en el caso materia que analizaré como ejemplo en la presente investigación. Por lo pronto, hasta este punto podemos identificar el estado de la cuestión.

\section{Las máximas de experiencia. Estructura y naturaleza de sus enunciados}

Las máximas de experiencia han sido concebidas desde la doctrina como criterios o reglas de valoración de las pruebas que pertenecen al sistema de valoración racional o de sana crítica bajo el cual se guía nuestro sistema procesal. Las máximas de experiencia se constituyen en herramientas o medios empleados para la adecuada valoración judicial.

Poseen una función instrumental en la actividad de valoración, que permitirán arribar a las conclusiones a partir de los datos fácticos con los que se cuenta. Este también es el sentido que se encuentra prescrito legalmente en el CPP, cuando señala de modo taxativo que: "en la valoración de la prueba el juez deberá observar las máximas de la experiencia" (art. 158.1 del CPP) y "la valoración probatoria respetará las reglas de la sana crítica, especialmente (...) las máximas de la experiencia y los conocimientos científicos". De ahí que las máximas de experiencia no sean en sí mismas reglas de la sana crítica, sino que se instauran como reglas para la valoración de acuerdo con la sana crítica. La citada redacción refuerza su función instrumental dentro de la valoración probatoria.

En igual sentido, la Corte Suprema peruana sostiene respecto de ellas lo que sigue:

- Las versiones poseen un sustento que debe ser valorado en su totalidad bajo el criterio de la sana crítica, pero respetando las reglas de lógica, la ciencia y las máximas de experiencia (Recurso de Nulidad 2148-2019).

- De modo que el Tribunal de Apelación, en cuanto al material probatorio, tiene la potestad jurídica de apreciar el juicio de valorabilidad de las pruebas (su admisión y actuación conforme con la legalidad procesal) y el juicio de apreciación probatoria (si esta es fiable, de cargo, corroborada y suficiente, y si se respetaron los cánones de corrección de la regla de inferencia probatoria; es decir, la determinación y el uso adecuado de las máximas de experiencia, conocimientos científicos y/o leyes de la lógica pertinentes) (Apelación 25-2017).

- Cuando se trata de la prueba habitualmente conocida como indiciaria, para que la conclusión incriminatoria pueda ser tenida por válida, es preciso que los hechos indiciarios o hechos base sean varios e incidan sobre el hecho principal u objeto de imputación, que estén probatoriamente bien acreditados, mediante prueba de la llamada directa, que la inferencia realizada a partir de aquellos sea racional y fundada en máximas de experiencia fiables, y, en fin, que cuente con motivación suficiente (Casación 475-2019).

Por otra parte, se ha indicado que las máximas de experiencia serían consideradas normas jurídicas, mientras que, por otro, se rebate esta posición señalando que son reglas de índole empírica o fáctica. Esta última es la postura que asumiré. Las máximas de la experiencia "no puede comprenderse como un de tipo normativo o prescriptivo, constituyen un medio o un instrumento -un enunciado general descriptivo, con proyección empírica-" (Limardo, 2021, p. 129) que deben ser empleados en concordancia con la apreciación racional de la prueba.

Ahora bien, por qué decimos que las máximas de experiencia consisten en enunciados descriptivos y no en enunciados normativos o prescriptivos. Citaré los siguientes ejemplos que han sido asumidos por la jurisprudencia de la Corte Suprema de Justicia del Perú respecto de las denominadas máximas de experiencia:

a) Según las máximas de experiencia, se atribuye al imputado (adulto, que incluso tiene una pareja) el conocimiento de la minoría de edad de la víctima (Recurso de Nulidad 2465-2018-Lima Sur). 
b) Conforme a las máximas de la experiencia, los litigantes buscan a los abogados defensores recomendados por otras personas, más no por estar cerca sus oficinas a la Fiscalía o al Poder Judicial (Apelación 18-2018-San Martín).

c) Conforme a las máximas de experiencia, la menor estaría mejor con la figura femenina del hogar, dado que necesita orientación de su madre por su edad al entrar a una etapa de cambios corporales y psíquicos, siendo, que dichos cambios deben afrontados por la figura materna (Casación 1765-2018-Ica).

Sin realizar un análisis crítico o cuestionar si las citadas máximas de experiencia que asumen nuestros tribunales de justicia son correctas o no, veamos la formulación de sus enunciados. En definitiva, no se trata de afirmaciones de índole imperativa sino más bien de carácter descriptivo. A mayor detalle, Hernández (2013, p. 15) explicita las diferencias. Así, los enunciados prescriptivos pueden ser pasibles de ser cumplidos o incumplidos, eficaces e ineficaces y se expresan de modo imperativo como: no fumar en lugares públicos. Pueden constituir una norma, una orden, mandato o incluso un consejo. Estas formulaciones no son susceptibles de ser verdaderas ni falsas a diferencia de los enunciados de carácter descriptivos.

Así, Hernández (2015, p. 15) sostiene que los enunciados descriptivos también llamados asertivos, aseverativos, o declarativos son enunciados susceptibles de ser catalogados como verdaderos o falsos. Por consiguiente, en la citada jurisprudencia, la formulación de las denominadas máximas de experiencia se expone como enunciados de esta clase. De ahí que se descarte que las máximas de experiencia sean normas o reglas de índole jurídica, en tanto, no expresan ninguna orden o mandato, sino que su enunciación es susceptible de veracidad o derrotabilidad de comprobarse su falsedad.

Entonces las máximas de experiencia son formuladas mediante enunciados que describirán de modo general un determinado suceso o sucesos de la realidad; es decir, son generalizaciones de carácter empírico por ser tomadas o percibidas del mundo real. Justamente, el que coincidan o no con la realidad convierten a las generalizaciones en enunciados derrotables.

Ahora bien, tenemos hasta aquí que las máximas de experiencia son generalizaciones de carácter empírico o fáctico formuladas de modo descriptivo. Conviene identificar su estructura. Los ejemplos jurisprudenciales citados previamente pueden ser reconstruidos del siguiente modo:

a) Un imputado que es mayor de edad suele conocer la edad de la víctima.

b) Los litigantes suelen buscan a los abogados defensores recomendados por otras personas.

c) Una menor suele estar mejor con su madre por ser una figura femenina.
Se aprecia que normalmente, la formulación de las generalizaciones posee el tipo condicional: "Si se da la condición A entonces se produce B". Así las condiciones serían el imputado mayor de edad, los litigantes y las menores; mientas que las consecuencias estarían constituidas por: suelen conocer la edad de la víctima, buscan defensores recomendados y están mejor con su madre por ser una figura femenina, respectivamente.

En ese sentido, el antecedente del enunciado estaría constituido por una condición y el consecuente por una propiedad vinculada causalmente a la constatación de ese antecedente; es decir, la estructura lógica de las generalizaciones empíricas se expresaría "Si p, entonces q", lo enunciados que presentan esta forma son denominados enunciados condicionales.

Un enunciado condicional afirma que en caso que su antecedente sea verdadero su consecuente también lo es el "significado esencial de un enunciado condicional es la relación que este afirma que existe entre el antecedente y su consecuente, por lo que, para comprender el significado de un enunciado condicional debemos comprender cuál es la relación de implicación" (Copi \& Cohen, 2013, p. 379). El antecedente y el consecuente de los enunciados poseen un referente empírico que es contrastable y se expresa entre ellos una implicación causal que determina que la conexión entre ellos deba (o pueda) descubrirse empíricamente (Limardo, 2021, p. 126).

Debe acotarse entonces que se las generalizaciones empíricas se expresan como enunciados condicionales que son susceptibles de verificación de verdad o falsedad; es decir, son enunciados derrotables. Al respecto, Anderson acota que "en la práctica es raro que la generalización de la que depende la justificación de una inferencia sea una proposición universalmente verdadera, comúnmente tienen cuantificadores difusos tales como suele", (2015, p. 140). Así se reformularon los enunciados en la jurisprudencia citada en los apartados previos, el antecedente (condición) está unido al consecuente 
(característica o propiedad) a través de los cuantificadores como los siguientes: "suele, en la mayoría de casos, en mayor medida, casi siempre”, entre otros, los cuales revelan el grado o fuerza de la correlación.

Al respecto, Limardo (2021, p. 126) explica que la verdad del enunciado condicionante dependerá de: (i) la constatación de un vínculo o correlación entre condición y consecuencia y (ii) la verificación del grado de intensidad de la correlación expresado en el enunciado "suele, en la mayoría de casos, en mayor medida, entre otros".

Ahora bien, como bien refieren Anderson, Schum \& Twinnin (2015, p. 140) en la mayoría de los contextos, el razonamiento inductivo opera intuitivamente. Esto significa que quien razona no identifica conscientemente las generalizaciones de las que dependen sus inferencias, a menos que sea requerido a justificar sus conclusiones. De ahí que consideran relevante que en el escenario jurídico sea importante identificar las generalizaciones sobre las que dependen las inferencias con el fin genuino de "determinar la fuerza o la plausibilidad de la inferencia e identificar potenciales falacias. Tanto la importancia como los potenciales peligros".

Precisamente, en las decisiones judiciales se constituye en una exigencia identificar la generalización de la inferencia del juez para así determinar si es que esta es aplicada lógicamente para justificar la inferencia o si se trata de una falacia o prejuicio que se ha ocultado detrás de la generalización. Antes de ello, incumbe establecer cuál es el lugar y rol que ocupan las generalizaciones empíricas en la valoración probatoria a partir de la teoría de la argumentación.

\subsection{Las generalizaciones empíricas en la valoración de la prueba}

Schum considera que las generalizaciones "representan el pegamento que mantiene unido nuestros argumentos", esto significa que cada inferencia que realizamos depende de una generalización (Anderson et al., 2015, p. 140). Antes de ello, debe precisarse que una inferencia consiste en un tipo de razonamiento. Por ejemplo, en la opinión de Gonzáles (2012, p. 20), es un razonamiento que realizamos a partir de la información proporcionada por nuestras percepciones.El citado profesor distingue los elementos de la inferencia: (i) los hechos a probar, (ii) la información disponible o las pruebas o hechos probatorios, y (iii) una relación entre (i) y (ii). Para lograr una mejor comprensión sobre la teoría de la argumentación y ubicar el rol que desempeñan las denominadas máximas de experiencia dentro del razonamiento jurídico, me sirvo del esquema del Toulmin.

Toulmin considera que todo argumento posee como elementos los siguientes (2018, p. 55): tesis (claims) y descubrimientos, bases (grounds), garantía (warrants) y respaldo (backing). En ese entender:
- Tesis: consisten en aquellas las afirmaciones o enunciados de algún sujeto presentados públicamente para su aceptación general. Si la tesis es jurídica, el alegato inicial se convierte en un veredicto, y sus consecuencias revestirán la forma de una orden o sentencia judicial (pp. 59-60). Su formulación sería, por ejemplo, $Z$ afirmo que $X$ sucedió.

- Bases: ahora bien, cada tesis o afirmación deberá encontrarse apoyada por las que denomina bases, consistentes en enunciados que especifican hechos particulares sobre una situación. Estos hechos serían aceptados como verdaderos y se constituyen en apoyo para aclarar y validar la tesis anterior, o -en el mejor de los casos- para establecer su verdad, corrección o solidez (p. 70). Responde a la pregunta hacia $Z$ ¿qué tienes para sostener que $X$ sucedió?

- Garantía: se tratan de enunciados que indican cómo los hechos con los que estamos de acuerdo se hallan conectados con la tesis o conclusión que se ofrece. Son enunciados de unión que, básicamente, expresan la regla del procedimiento general en que el proponente $\mathrm{Y}$, se está apoyando al presentar el paso de las bases a la tesis como un paso fiable que es seguro dar (pp. 79-81). La pregunta hacia $Z$ esta vez se formula así ¿cómo llegas a sostener que $X$ sucedió a partir de las bases que afirmas? Esta categoría en la estructura del razonamiento es la que puede identificarse como las llamadas máximas de experiencia.

- Respaldo: ahora bien, enunciar la garantía es una cosa, pero mostrar que se puede confiar en ella porque es sólida, pertinente e importante es algo distinto (p. 102). Cómo Z, demostrará que la garantía que emplea es superior a otras; precisamente, entra en juego el respaldo. Este elemento responde a la pregunta ¿es fiable o sólida esa garantía?

Las generalizaciones empíricas se constituirían en el marco de la argumentación de un proceso judicial en las garantías, que serían básicamente aquellos enunciados de índole hipotética o condicionales de la 
forma "Si p, entonces q", como se mencionó anteriormente. En postura de Toulmin (2007, p. 141) la garantía "es algo más que la repetición de los hechos aducidos, es una moraleja o consecuencia general de carácter práctico sobre la manera en que se puede argumentar con seguridad a la vista de los hechos". En la misma postura doctrinaria, González afirma que la garantía (siguiendo el esquema argumental de Toulmin) estaría constituida por las máximas de experiencia y las presunciones que según opina cumplen una función semejante en la inferencia probatoria y tienen estructura similar $(2012$, p. 21).

Ahora bien, si nos encontramos en un sistema de sana crítica o de valoración libre, la prueba involucra que también el uso de las máximas de experiencia se encuentre adecuadamente justificado y que sea controlable a través de la motivación. En este sentido, Fernández (2021, p. 365) señala que "solo a través de la motivación es posible llegar a conocer las razones que justifican la declaración de hechos probados". Entonces, de acuerdo con este principio, se exige que todo uso de una generalización se encuentre explicitado en el razonamiento judicial. En sentido opuesto, el uso (inadecuado) de las generalizaciones conlleva a la existencia del peligro de que sirva para justificar conclusiones basadas en prejuicios u opiniones personales del juez que no son objetivos, y, por el contrario, se encuentren cargados de arbitrariedad $o$ subjetividad que no es controlable de forma racional.

Acota Ramírez (2020) que:

Las certezas subjetivas que pudiera tener el juzgador sobre lo que pudo ocurrir son irrelevantes, pues el plano psicológico, al que pertenece el convencimiento, no siempre coincide con el racional, en el que se enmarca la valoración probatoria como actividad justificada sobre la base de su adecuación a criterios normativos universales y explicitables (p. 212).

A continuación, del marco teórico expuesto analizaré el caso concreto materia de análisis de la presente investigación en función de las perspectivas epistémica y de género que asumo.

\section{Análisis de jurisprudencia}

El caso que analizaré en el presente trabajo a efectos de aplicar el razonamiento y evidenciar las críticas anteriormente expuestas, se trata de la sentencia expedida por el Juzgado Penal Colegiado Supraprovincial Transitorio Zona Sur de la Corte Superior de Justicia de Ica - Perú (Exp. 2822-201990-Ica), el cual mediante la resolución del 8 de octubre del 2020(12), absolvió al procesado Giancarlos Miguel Espinoza Ramos como autor del delito contra la libertad sexual - violación sexual, previsto en el artículo 170 del Código Penal, en la modalidad "aprovechándose de cualquier otro entorno que impida a la persona dar su libre consentimiento", en agravio de la persona identificada con las iniciales J.E.P.M. de 20 años de edad.

En este caso, el colegiado emitió su decisión absolutoria de primera instancia fundamentando su valoración en el uso de sus máximas de experiencia, de modo concreto, en el considerando 35 efectuó el siguiente razonamiento:

35. Un hecho singular que no pasa desapercibido por este Tribunal y llama la atención que según los psicólogos Calle Arévalo como De La Cruz Nieto, quienes examinaron a la agraviada coinciden en señalar que "es una mujer tímida, muestra una actitud pasiva, dificultades para poder ser asertiva y poder decir no, de una manera tajante, lo cual se refleja a través de su timidez, dificultades para tomar decisiones y también que la colocan de alguna manera en una posición de sumisión frente a otras personas (...)" (...) "rasgos de personalidad dependiente con tendencia a la introversión, ese tipo de personalidad se caracteriza por ser una persona sensible, indefensa, sumisa, con cierta inmadurez se percibe como débil y frágil (...)" (...) sin embargo, suele vestir prendas interiores como la descrita por la bióloga forense Doris Matilde García Espinoza en su dictamen de biología forense 201907000119 , describiéndolo "(...) trusa femenina de color rojo con encaje en zona delantera, blondas en contorno de pierna (...)" resultando extraño que la supuesta personalidad que presenta la misma (tímida) no guarde relación con la prenda íntima que utilizó el día de los hechos, pues por las máximas de la experiencia este tipo de atuendo interior femenino suele usarse en ocasiones especiales para momentos de intimidad, por lo conlleva a inferir que la agraviada se había preparado o estaba dispuesta a mantener relaciones sexuales con el imputado (transcripción textual).

Los jueces determinaron que el imputado no cometió el delito de violación sexual contra la señalada agraviada en la modalidad "aprovechándose de cualquier otro entorno que impida a la persona dar su libre consentimiento". Su razonamiento esquematizado en la estructura de Toulmin, se expresaría del siguiente modo:

(12) Véase la sentencia en https://img.Ipderecho.pe/wp-content/uploads/2020/10/Exp.-002822-2019-LP.pdf 


\section{Figura 1}

\section{Razonamiento judicial en el esquema de Toulmin}

\begin{tabular}{|c|c|c|}
\hline $\begin{array}{l}\text { T: La agraviada se } \\
\text { encontraba preparada } \\
\text { y predispuesta a } \\
\text { mantener relaciones } \\
\text { sexuales con el presunto } \\
\text { imputado, ella prestó su } \\
\text { consentimiento para } \\
\text { el acto. }\end{array}$ & & $\begin{array}{l}\text { B: El día de los } \\
\text { hechos la presunta } \\
\text { agraviada estaba } \\
\text { usando una trusa de } \\
\text { color rojo con encaje } \\
\text { en zona delantera y } \\
\text { blondas en contorno } \\
\text { de la pierna. }\end{array}$ \\
\hline & $\begin{array}{l}\text { G: "La mujer que } \\
\text { usa una trusa } \\
\text { de color rojo con } \\
\text { encajes y blondas, } \\
\text { está dispuesta } \\
\text { a ma nte ner } \\
\text { r e I a c i o n e s } \\
\text { sexuales". }\end{array}$ & \\
\hline
\end{tabular}

Fuente: Elaboración propia

El paso de las bases a la tesis que realizó el tribunal se apoyó en la garantía constituida por una generalización empírica (máxima de experiencia), que unió su conclusión y el argumento que apoyó su conclusión. Como se indicó antes, la garantía expresada en la máxima de experiencia formula una regla de procedimiento general, a través de un enunciado condicionante. La verdad de un enunciado condicionante va a depender, en primer término, de la existencia del vínculo o correlación entre condición y consecuencia y, en segundo lugar, de la verificación del grado de intensidad de la correlación.

En el caso, si reconstruimos la generalización empírica que efectúa el juez y que no la explicita en su razonamiento, esta sería la siguiente:

- "La mujer que usa una trusa de color rojo con encajes y blondas suele estar dispuesta a mantener relaciones sexuales con el sujeto con quien se reúne".

Formulado en forma de enunciado condicional:

- "Si una mujer usa una trusa de color rojo con encajes y blondas, entonces, está dispuesta a mantener relaciones sexuales".

En el caso:

- La condición sería: una mujer que usa una trusa de color rojo con encajes y blondas, entonces, la característica o propiedad: está dispuesta a mantener relaciones sexuales.

El problema se vincula con el uso inadecuado de las inferencias probatorias de los jueces de primera instancia, en tanto que su conclusión concretamente consistente en que: el uso de una prenda íntima de color rojo se constituye en una máxima de experiencia respecto a que la presunta agraviada "estaba dispuesta a mantener relaciones sexuales con el investigado". Es un tipo de inferencia fundamentada en un prejuicio de género no en una generalización empírica justificada de forma racional.

En el razonamiento del juez no existe una garantía satisfactoria que sustente el razonamiento judicial. La base B: "El día de los hechos la presunta agraviada estaba usando una trusa de color rojo con encaje en zona delantera y blondas en contorno de la pierna", es insuficiente para legitimar su tesis o conclusión T: "La agraviada se encontraba preparada y predispuesta a mantener relaciones sexuales con el presunto imputado, ella prestó su consentimiento para el acto". Esto significa que el paso de B a T está claramente injustificado, ello en tanto no está apoyado en una valoración racional sino que estriba en una garantía inverosímil, por lo cual, no es posible verificar el grado de correlación existente.

Como lo refiere Toulmin:

Enunciar una garantía es una cosa, pero mostrar que se puede confiar en ella porque es sólida, pertinente e importante es otra cosa distinta (...) las garantías no se validan a sí mismas. Nuestras garantías y modos de razonamiento que autorizan normalmente extraen su fuerza y su solidez de otras consideraciones sustanciales de apoyo ( $p$. 102).

Si no ocurriera ello, la garantía que une su premisa y conclusión no poseería un respaldo racional. Entonces ¿en qué se fundamenta la generalización empírica señalada por el tribunal? Precisamente, entran en dicho escenario los sesgos o prejuicios de género, que fueron estudiados en el segundo epígrafe de la presente investigación.

En el caso, si analizamos el razonamiento judicial que fundamentó la sentencia absolutoria por el delito de violación sexual se puede apreciar que no se basa en un criterio de racionalidad, su razonamiento no ha sido debidamente expuesto ni justificado. A mi entender, el nexo que unió su base a la tesis que sostiene es evidentemente débil y se ha creado a partir de lo que se denomina 
un prejuicio de género, identificable si realizamos un análisis desde una perspectiva de género, veamos a continuación.

\subsection{Estereotipos de género revestidos de máximas de experiencia en el caso analizado}

Retomando la resolución analizada, se pueden identificar concretamente en esta los siguientes estereotipos sexuales: (i) las mujeres que muestran actitudes tímidas y pasivas tienen dificultades en la toma de sus decisiones y, por tanto, se les hace difícil decir "no" de manera tajante; (ii) las mujeres sensibles, indefensas y sumisas con personalidad inmadura son débiles y frágiles y usan prendas de vestir de acuerdo con esta personalidad, por lo que, (iii) una mujer con personalidad tímida o sumisa no podría usar prendas de vestir tales como una "trusa de color rojo con encaje en zona delantera y blondas en el contorno de la pierna"; en ese entender, (iv) si una mujer usa el tipo de prendas interiores descritas, se infiere que se prepara o está dispuesta a mantener relaciones sexuales con el imputado.

Si la interpretación se realiza en concordancia con una perspectiva epistémica y específicamente de género, se puede identificar los distintos sesgos o estereotipos sobre determinados hechos respecto de los cuales se fundamenta una decisión ${ }^{(13)}$. En ese sentido, lo que se pretende con esta puesta en evidencia es que la actividad valorativa del juez:

Suprima todos aquellos estereotipos discriminatorios que de forma consciente o inconsciente han alcanzado la consideración de máximas de experiencia elevando a tal categoría lo que no son sino consecuencias históricamente asumidas de un entendimiento de la sociedad basado en una artificial atribución de roles (Fuentes, 2020, pp. 280-281).

En el caso, el juez aplicó un estereotipo sobre el rol de la mujer como sumisa y tímida y el estereotipo sexual de que este rol es incompatible con el uso de determinadas prendas de vestir, como trusas de color rojo, y que, por el contrario, de su uso, se infiere que tiene predisposición a mantener relaciones sexuales. En definitiva, se trata de una seria problemática en el razonamiento judicial, porque el juez tiene como punto de partida este prejuicio de género, lo cual puede conllevar a infravalorar el valor probatorio de la declaración la víctima o incluso de las demás pruebas que podrían obrar en el caso concreto, o en el peor de los casos busque que estas reafirmen su interpretación ${ }^{(14)}$ sesgada (sesgo de confirmación).

Adicional a ello, resulta conveniente identificar cuáles son las problemáticas probatorias en la sentencia en revisión.
También este criterio podría verse reforzado a través de la jurisprudencia sucesiva que aplique este razonamiento y que genere algún tipo de precedente en la aplicación de futuros casos. Al respecto, es pertinente la afirmación de Ibáñez (2020) cuando refiere que la jurisprudencia como "fenómeno jurídico-institucional no puede perder de vista que es el resultado final de muy plurales aportaciones, de actores que deben gozar de independencia interna para operar con exclusiva sujeción a la ley y a criterios de racionalidad cognoscitiva" (p. 84).

Fundamentándose en lo que según el tribunal consideró una máxima de experiencia, se concluyó que la presunta agraviada prestó su consentimiento para los actos sexuales basándose en la premisa de que el día de los hechos usaba una trusa de color rojo, la cual, según sus máximas de experiencia, le permitieron inferir que esta tenía intención de mantener relaciones sexuales con el imputado. Como se indicó, las conclusiones del juez de primera instancia se fundamentan en prejuicios o sesgos no controlables objetivamente. Se trata de un razonamiento que funda su conclusión sobre la base de una inferencia basada en un prejuicio sexista.

Una de las formas de controlar el razonamiento es la debida motivación que exige que todas las decisiones judiciales se encuentren debidamente justificadas. En el caso concreto, el juez ha recurrido al uso de sus máximas de experiencia para concluir que la víctima consintió el acto. Su exposición de motivos da lugar a cuestionarse si es que está realizando un adecuado empleo o uso de las denominadas máximas de experiencia en las decisiones judiciales. Por ello, como lo expuso Anderson, en los razonamientos judiciales es de suma relevancia que se identifiquen las generalizaciones sobre las que depende la inferencia del juez para poner en evidencia si estas son plausibles o se tratan más bien de potenciales falacias o peligros.

(13) En esa interpretación, Gama cuando sostiene que "la perspectiva de género puede servir para ilustrar, la manera en que las construcciones de género están presentes en la selección y formulación de los hechos jurídicamente relevantes” (2020, p. 293).

(14) Es importante tener en cuenta lo acotado por González Lagier cuando afirma precisamente que "las interpretaciones se basan en los datos sensoriales que recibimos de los hechos pero, por otro lado, de nuestra red de conceptos, categorías, teorías, máximas de experiencia, recuerdos, etc. (que constituyen un trasfondo necesario para interpretar los hechos) dirigen de alguna manera nuestras percepciones y actúan como criterio de selección de los datos sensoriales que recibimos" (González, 2005, p. 28). 
En ese entender, si nos encontramos en un sistema de sana crítica o de valoración libre, involucra que también el uso de las máximas de experiencia se encuentre adecuadamente justificado y que sea controlable a través de la motivación. Ahora bien ¿cuándo se encontraría justificado el uso de unas máximas de experiencia o generalización empírica? Coincido con Arena cuando sostiene que si se van a tomar decisiones acerca de un grupo o sobre la base de generalización estas generalizaciones debe contar con apoyo empírico (apoyo estadístico) y si es que estas decisiones perjudican a grupos vulnerables como las mujeres se privilegie la consideración de rasgos individuales frente a las posibles generalizaciones (incluso si poseen apoyo empírico) ${ }^{(15)}$, por lo que, en caso contrario la generalización debe ser descartada (Arena, 2020, p. 255).

En el presente caso, la libertad en la valoración así como sus criterios -específicamente, las máximas de experiencia- se han empleado de modo equívoco e inadecuado en perjuicio de una valoración acorde a las reglas de la racionalidad. Así se ha efectivizado el peligro de que su utilización sirva para justificar conclusiones basadas en prejuicios de género u opiniones personales del juez que no son objetivas, porque no se ha determinado que el estereotipo aplicado sea una norma social aceptada, no posee un apoyo empírico, y por el contrario, se encuentra cargada de arbitrariedad o subjetividad que no es controlable de forma racional. Como bien lo expresa la profesora Fernández (2007, p. 3) "la valoración libre no puede equipararse a valoración basada en la intuición, los sentimientos o los presentimientos del órgano judicial, pues ello convertiría a esta actividad en un acto de mero voluntarismo".

Por consiguiente, se concluye que, en el caso materia de análisis, no existe ninguna relación que permita inferir, como conclusión, el consentimiento de la víctima, a partir de la premisa que señala que el día de los hechos presuntamente delictivos usaba una prenda de color rojo. Así, la inferencia es infundada. El juez empleó inadecuadamente las llamadas máximas de experiencia para justificar una decisión atiborrada de prejuicios. Esta a todas luces, se despliega en desmedro de una valoración racional y epistémica del proceso, el cual debe evaluar de acuerdo a los elementos de juicio que se presenten en el caso -como la declaración de le víctima e imputado, pericias, documentos, entre otras pruebas que corroborarán el objeto de prueba y que determinarán la decisión judicial-. No se pueden obtener decisiones acertadas si es que no se aplican de acuerdo a criterios objetivos que superen la mera intuición del juzgador.

\section{Conclusiones}

La valoración de la prueba debe orientarse bajo una concepción racional o cognoscitiva del proceso que implica asumir que la determinación de la verdad es el fin institucional del proceso y de la prueba. En esa línea de razonamiento, la apreciación de la prueba involucra el empleo de criterios de racionalidad y objetividad controlables a través de una adecuada motivación. Para el desarrollo de la presente investigación, también me sirvo de una visión desde perspectiva de género que permite poner en evidencia y cuestionamiento los razonamientos judiciales que se aparten de una concepción racionalista del proceso y que, en sentido opuesto, se inclinen por la aplicación de razonamientos fundamentados en estereotipos o sesgos de género que contravienen la concepción epistémica del proceso.

Las denominadas máximas de experiencia son empleadas como criterios de valoración probatoria, así lo han consignado la legislación, doctrina y jurisprudencia (aunque con matices diversos). La importancia de su aplicación en el razonamiento judicial y la toma de decisiones es esencial. Por ende, una interpretación y aplicación correcta de estos criterios de apreciación es imperativo para cumplir con un sistema de valoración racional. en el presente trabajo, que las máximas cumplen un rol instrumental en la valoración probatoria. Consisten en formulaciones o enunciados descriptivos o declarativos de índole empírica y se tratan de generalizaciones de carácter empírico que son susceptibles de ser calificados de verdaderos o falso.

La formulación de las generalizaciones empíricas posee un tipo condicional. Por

(15) Como bien lo acota Gama: "muchas de las generalizaciones de sentido común que se emplean habitualmente en el razonamiento probatorio operan silenciando las experiencias de aquellas personas cuyo comportamiento no se adecua a la regla general". El mismo autor citando a MacCrimmon refiere que "las diferentes experiencias y perspectivas de las mujeres no han sido incorporadas en la forma de decisiones jurídicas y que la incorporación de estas experiencias requiere de un examen autoconsciente y deliberativo de los esquemas y generalizaciones que operan en cada caso individual. No puede asumirse que las experiencias de las mujeres son parte del conocimiento de sentido común" (2020, p. 294). 
ende, son enunciados condicionales y dentro del esquema de argumentación de Toulmin se constituyen en garantías que permitirán justificar el paso de los hechos (base) a la conclusión (tesis). Su empleo debe ser adecuado, porque pueden ser empleadas para justificar conclusiones fundadas en prejuicios de índole sexista, como en el caso materia de análisis.

Así, en este se han identificado que el razonamiento judicial se empleó bajo un sesgo o estereotipo de género, arguyendo el consentimiento de la víctima de mantener relaciones sexuales con el imputado sobre la base de que usaba una prenda íntima de color rojo y con características que, a consideración del tribunal, permitían inferir su predisposición a mantener relaciones sexuales con el imputado. El empleo de las generalizaciones empíricas en el caso concreto no se encuentra justificado racionalmente. Al respecto debe acogerse lo señalado por Fernández (2021) cuando precisa que "la racionalidad de una decisión no se supone ni se presume, sino que debe ser siempre puesta en duda mientras no aparezca debidamente justificada" (p. 364). En el caso concreto, por el contrario, bajo la denominada máxima de experiencia se han ocultado criterios subjetivos que responden a estereotipos sobre el rol sexual de la mujer.

En escenarios procesales futuros, resulta fundamental superar los estereotipos de género que han sido comúnmente aceptados y que se cobijan bajo una máxima de experiencia o generalización de índole empírica, así como evitar los sesgos cognitivos sobre los cuales se fundan. El fin epistémico del proceso, así como el rol de la perspectiva de género es de relevancia en la actividad probatoria, pues permitirá identificar y poner en tela de juicio aquellos argumentos que se conciban sobre la base de prejuicios y sesgos de carácter sexista que han venido justificando decisiones de absolución y condena en detrimento de una adecuada valoración racional de la prueba.

\section{Referencias bibliográficas}

Abel, X. (2012). Derecho probatorio (1. a ed.). Bosch Editor.

Accatino, D. (2018). Apuntes sobre el concepto de prueba en el derecho. Curso Máster de Razonamiento Probatorio.

Anderson, T., Schum, D. \& Twining, W. (2015). Análisis de la prueba. (F. Carbonell \& C. Agüero, trad.). Marcial Pons.

Andrés, P. (2020). En materia de prueba: sobre algunos cuestionables tópicos jurisprudenciales. Quaestio facti. Revista Internacional sobre Razonamiento Probatorio, 1, 75-102. http://dx.doi.org/10.33115/ udg_bib/qf.i0.22364.

Arena, F. (2020). Notas sobre el testimonio único en casos de violencia de género. Quaestio facti. Revista Internacional sobre Razonamiento Probatorio, 1, 247-258. http://dx.doi.org/10.33115/udg_bib/qf.i0.22370.
Bonorino, P. (2016). La racionalidad judicial y el uso de las reglas de la sana crítica. En: El derecho probatorio y la decisión judicial. Universidad de Medellín.

Cerda, R. (2011). El nuevo proceso penal. Constitucionalización, principios y racionalidad probatoria. Editora Jurídica Grijley.

Clariá Olmedo, J. (1998). Derecho procesal penal (Tomo II). Rubinzal Culzoni Editores.

Copi, I. \& Cohen, K. (2013). Introducción a la lógica (2. ${ }^{\text {a }}$ ed.). Limusa.

Fernández López, M. (2005). Prueba y presunción de inocencia (1. ${ }^{\mathrm{a}}$ ed.). lustel.

Fernández López, M. (2007). La valoración de pruebas personales y el estándar de la duda razonable. Cuadernos electrónicos de Filosofía del Derecho, 5, 1-12.

Fernández López, M. (2021). Deliberación y motivación del veredicto. Las facultades del magistrado-presidente del tribunal del jurado. Indret, 1, 355-376.

Ferrer, J. (2005). Prueba y verdad en el derecho (2. ${ }^{a}$ ed.). Marcial Pons.

Ferrer, J. (2007). La valoración racional de la prueba. Marcial Pons.

Ferrer, J. (2016). Motivación y racionalidad de la prueba. Editora Jurídica Grijley.

Fuentes, O. (2020). La perspectiva de género en el proceso pena ¿Refutación? De algunas conjeturas sostenidas en el trabajo de Ramírez Ortiz "EI testimonio único de la víctima en el proceso penal desde la perspectiva de género". Quaestio facti. Revista Internacional sobre Razonamiento Probatorio, 1, 271-284. http://dx.doi.org/10.33115/ udg_bib/qf.i0.22372.

Gama, R. (2020). Prueba y perspectiva de género. Un comentario crítico. Quaestio facti. Revista Internacional sobre Razonamiento Probatorio, 1, 285-298. http://dx.doi.org/10.33115/udg_bib/ qf.i0.22373.

Gimeno, V. (2012). Derecho procesal penal (3. ${ }^{\text {a }}$ ed.). Thomson Reuters.

González Lagier, D. (2005). Quaestio facti. Ensayos sobre prueba, causalidad y acción. Palestra.

González Lagier, D. (2012). Apuntes sobre prueba y argumentación jurídica. Repositorio institucional de la Universidad de Alicante.

Hernández, R. (2013). Razonamientos en la sentencia judicial. Marcial Pons.

Horvitz, M. \& López, J. (2004). Derecho Procesal Penal chileno (Tomo I). Editorial Jurídica de Chile. 
Limardo, A. (2021). Repensando las máximas de experiencia. Quaestio facti. Revista Internacional sobre Razonamiento Probatorio, 1, 115-153. http:// dx.doi.org/10.33115/udg_bib/qf.i2.22464.

Maier, J. (2004). Derecho procesal penal. Parte general. Actos procesales (2. ${ }^{a}$ ed., Tomo III). Editores del Puerto.

Montero, J. (2008). Proceso penal y libertad. Ensayo polémico sobre el nuevo proceso penal. Thomson Civitas.

Ramírez, J. (2020). El testimonio único de la víctima en el proceso penal desde la perspectiva de género. Quaestio facti. Revista Internacional sobre Razonamiento Probatorio, 1, 205-246. http:// dx.doi.org/10.33115/udg_bib/qf.i0.22288
San Martín, C. (2015). Derecho Procesal Penal. Lecciones. Instituto Peruano de Criminología y Ciencias Penales.

Stein, F. (1999). El conocimiento privado del juez (2. ${ }^{a}$ ed.) (Andrés de la Oliva Santos, trad.). Temis.

Talavera, P. (2009). La prueba en el nuevo proceso penal. Academia de la Magistratura.

Taruffo, M. (2009). La prueba, artículos y conferencias. Editorial Metropolitana.

Taruffo, M. (2011). La prueba de los hechos (4. ${ }^{\text {a }}$ ed.) (J. Ferrer, trad.). Trotta.

Toulmin, S., Rieke, R. \& Janik, A. (2018). Una introducción al razonamiento (J. Gascón, trad.). Palestra. 